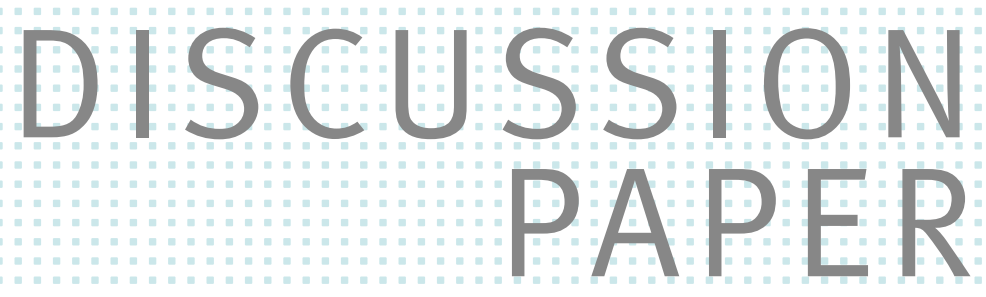

// JOST H. HECKEMEYER, KATHARINA NICOLAY, AND CHRISTOPH SPENGEL

\title{
What Will the OECD BEPS Indicators Indicate?
}




\title{
What Will the OECD BEPS Indicators Indicate?
}

\author{
Jost H. Heckemeyer \\ Kiel University \& ZEW Mannheim \\ Katharina Nicolay \\ University of Mannheim \& ZEW Mannheim \\ Christoph Spengel \\ University of Mannheim \& ZEW Mannheim
}

\section{Summary}

- As part of its action plan against base erosion and profit shifting (BEPS), the OECD (2015) has proposed six indicators to measure profit shifting activity. These indicators add to past and ongoing efforts in academic tax research to empirically identify the scale and tax sensitivity of international profit shifting. In this paper, we discuss whether the proposed OECD indicators indeed represent methodological advances and critically assess their informative value.

- While a certain need for "easy-access" indicators to measure the relevance of the base erosion problem seems justified, our discussion reveals that the indicators come up with certain shortcomings, many of them acknowledged by the OECD (2015) itself, that prevent them from reliably tracing profit shifting activity in available international data. With one notable exception, the OECD's indicators lack consistent counterfactuals and comparison groups which are essential benchmarks for the observed data.

- Even the most promising approaches require representative and timely data that covers firms' global activity, including tax haven operations. With better access to such highquality micro-level data, it will be more promising to empirically isolate the effects of profit shifting from relocations of real economic activity and value creation.

JEL: H20, H25, H26

Keywords: Tax policy, International Taxation, BEPS, OECD, Base Erosion and Profit Shifting

This version: January 2021

Paper prepared for the European Tax Policy Forum (ETPF) 2017

Jost H. Heckemeyer: heckemeyer@bwl.uni-kiel.de

Katharina Nicolay: nicolay@zew.de

Christoph Spengel: spengel@uni-mannheim.de 


\section{Introduction}

The public debate on legal tax avoidance by multinational companies (MNCs) has been fueled by extremely low effective tax rates (ETRs) of highly profitable companies that seem to pay almost no corporate income tax in foreign source countries. For example, the most valuable US company, Apple Inc., reported a foreign (i.e. non-US) ETR of only $4.7 \%$ for the fiscal year 2011 (Sullivan 2012). The problem, of course, is not new and many countries have already implemented reforms to reduce the incentives for profit shifting or to strengthen anti-avoidance regulations. The European Commission also addresses the issue. On 12 July 2016 the European Council adopted the first Anti-Tax Avoidance Directive (ATAD 1) and complemented this new legislation with a second directive (ATAD 2) on 29 May 2017. ${ }^{1}$ Yet, with the increasing importance of knowledge capital and new distribution channels, there is a persistent call for monitoring, and ultimately combating, tax base erosion.

All of this suggests that the problem of tax base erosion is substantial. But how can we really know about the scale of profits shifted and taxes avoided? How can we measure tax base erosion and profit shifting, trace developments over time and judge about the effectiveness of countermeasures? As part of its action plan against base erosion and profit shifting (BEPS), the OECD (2015) has proposed six indicators to measure BEPS activity. These indicators add to past and ongoing efforts in academic tax research to empirically identify the scale and tax sensitivity of international profit shifting. Given that our current knowledge of income shifting behavior is still far from complete, every new indicator seems at least worth considering. In this paper, we discuss whether the proposed OECD indicators indeed represent methodological advances and critically assess their informative value.

In sum, our discussion reveals several shortcomings, many of them also acknowledged by the OECD (2015) itself, that prevent the proposed indicators from reliably tracing profit shifting activity in available international data. With one notable exception, the OECD indicators lack consistent counterfactuals and comparison groups which are, however, essential benchmarks for the observed data patterns. Only one of the proposed approaches to measure BEPS explicitly acknowledges the need for such a counterfactual benchmark and thus could form the basis of a reliable indicator, supposing sound and state-of-the-art statistical techniques are applied. We highlight existing previous applications of this promising approach in empirical tax research.

\footnotetext{
${ }^{1}$ Council Directive (EU) 2016/1164 of 12 July 2016 and Council Directive (EU) 2017/952 of 29 May 2017.
} 
This paper is organized as follows. Section 2 provides a very brief summary of what is known about the tax sensitivity of profit shifting to international tax incentives. Section 3 discusses the six OECD indicators one by one. Section 4 concludes.

\section{Evidence on International Tax Avoidance: The Tax Sensitivity of Reported Profits}

An important strand of empirical research provides compelling and robust evidence for tax motivated international profit shifting. Thus, we know that profit shifting by MNEs takes place. Recently, the ample literature has been reviewed by Dharmapala (2014), Riedel (2014), and Heckemeyer and Overesch (2017).

Previous empirical research mostly builds on a conceptual framework developed by Hines and Rice (1994) and enhanced by Huizinga and Laeven (2008). The basic rationale of this framework is that the observed pre-tax income of an affiliate is the sum of unobserved true pre-tax profits and a (positive or negative) shifted income component. Unobserved true pre-tax profits are equal to the affiliate's production output minus the wage bill, i.e. they reflect true value creation by the affiliate. Accordingly, the tax effect on profit allocation within MNCs is identified conditional on the inputs that enter the affiliate's production function in order to isolate the shifted income component from the genuine pre-tax profit. Specifically, the profit shifting component is identified by exploiting the (weighted) international tax rate difference between the affiliate and its parent or other entities of the MNE. The estimated coefficient of the tax term reflects the sensitivity of reported profits to international tax incentives. Quantitatively, it indicates the change in percentage of reported profit in response to a one percentage point change in the tax differential vis-à-vis other international locations (the semi-elasticity of reported pretax profits). Heckemeyer and Overesch (2017) present a meta-analysis of 27 empirical studies to synthesize the existing evidence on this semi-elasticity. They predict a semi-elasticity of about -0.8 . Taking this result at face value, a one percentage point cut in host country taxes is associated with an increase in the pre-tax profits of an affiliate by approximately $0.8 \%$.

Interestingly, considering the 238 primary estimates they draw from the empirical literature, Heckemeyer and Overesch (2017) find that more recent studies tend to report lower semi-elasticities than previous papers (see Figure 1). Thus, the question arises what may explain this downward trend in the estimated tax sensitivity of pre-tax profits? On the one hand, decreasing tax-rate elasticities could be due to advances in the empirical approaches used to identify income shifting behavior of multinational firms. Specifically, more recent studies often exploit richer data sources, firm-level panel data in particular. Using better data, these studies are able 
to employ rigorous micro-econometric techniques that may produce more precise and more accurate estimates of the genuine tax semi-elasticity. On the other hand, the observed negative trend could reflect increasing costs of income shifting due to tighter anti-avoidance legislation that many countries, including the European Union, have implemented to limit the incentives and opportunities for profit shifting.

Using meta-regression techniques, Heckemeyer and Overesch (2017) find that even conditional on the econometric specification, method and data, semi-elasticities exhibit a decreasing trend. However, the picture remains somewhat ambiguous. For example, Klassen and Laplante (2012) state that, even with tax rate differences held constant, U.S. MNEs have become more tax aggressive over the past two decades. Clausing (2016) is skeptical of the existent literature in view of the fact that it mostly relies on financial accounting data whereas tax returns would be the optimal source of information. Moreover, she argues that available financial data sets only have weak coverage of some important tax havens - a problem which she fears could lead to an underestimation of BEPS. In a recent study, Barrios and d'Andria (2016) propose that elasticities of profit shifting do not follow any long-term trend but display a pro-cyclical behavior with a decrease during crisis years and an increase in years of economic recovery.

After all, in the past two decades, our understanding of international profit shifting, its mechanisms and incentives have increased considerably. Still, our current knowledge of the diverse facets of profit shifting is far from complete. This justifies the search for additional indicators to monitor BEPS - as long as these present methodological advances. Whether the proposed OECD indicators provide reliable, additional or even better information on BEPS will be discusses in the next section.

\section{The Six OECD BEPS Indicators: What is their Rationale and Informative Value?}

In 2015, the OECD presented its final reports on 15 distinct actions as part of its plan to tackle base erosion and profit shifting (BEPS). Action 11 of the BEPS agenda presents six indicators that are supposed to measure and inform about the scale and the channels of BEPS. In the following, we will present the six BEPS indicators proposed by the OECD (2015) in its final report on action $11 .^{2}$ Given that the OECD's final report provides, on as much as 300 pages, a comprehensive detailed technical description which also comes with a frank discussion of the indi-

\footnotetext{
${ }^{2}$ OECD (2015), Measuring and Monitoring BEPS, Action 11 - 2015 Final Report, OECD/G20 Base Erosion and Profit Shifting Project, OECD Publishing, Paris. http://dx.doi.org/10.1787/9789264241343-en.
} 
cators benefits and weaknesses, our aim is to be as concise as possible and present these indicators in a non-technical, visual way stressing the idea rather than computational details. Moreover, we address those benefits and weaknesses that we consider the most relevant.

Figure 1 provides an overview of the six indicators. The indicators deal with different facets of BEPS and measure BEPS at different levels of aggregation. Whereas indicators 1 and 5 exploit macroeconomic data, the remaining indicators require firm-level data. Considering the computational aspects, most indicators are based on some form of benchmarking, regrouping and averaging of the data whereas, notably, indicator 4 uses econometric techniques. Thus, an apparent advantage of indicator 4 is that a counterfactual "pre-BEPS" situation can, by statistical means, be constructed and serve as a benchmark for estimates on the scale and prevalence of profit shifting. We will get back to this point.

\section{Figure 1: Overview of the six BEPS indicators}

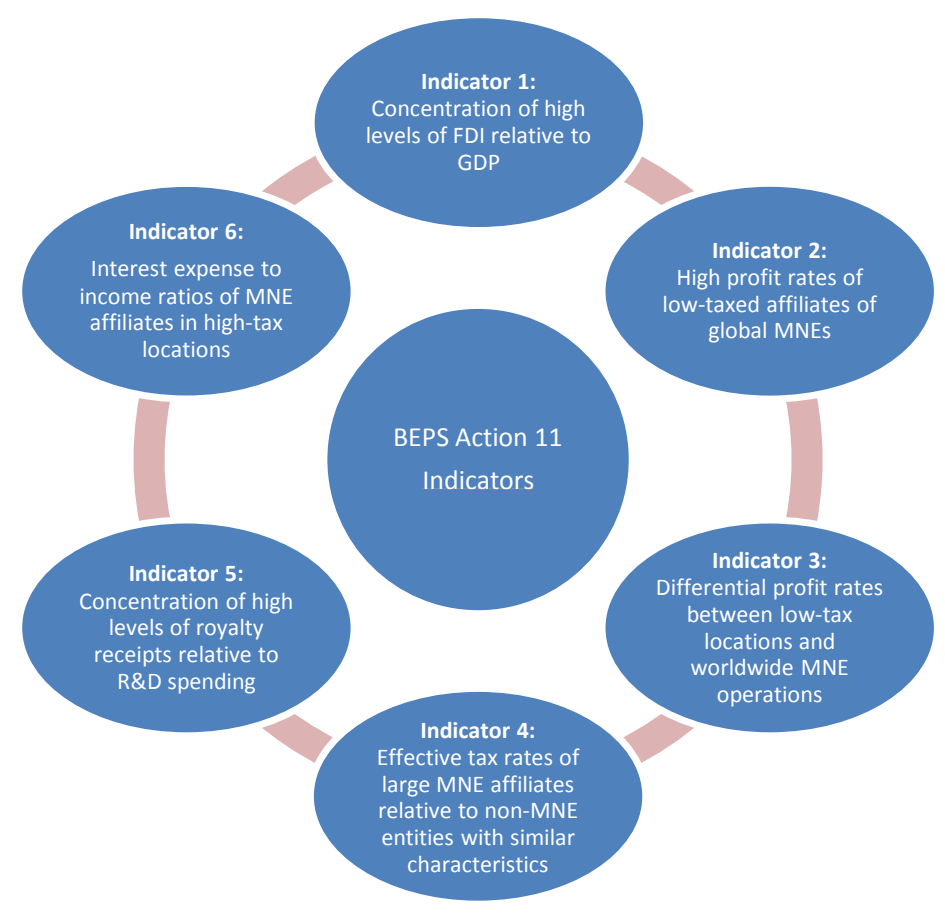

\section{Indicator 1: Disconnect between financial and real economic activities}

The so-called gravity approach explains inter-country trade patterns through a combination of mass variables (e.g. GDP, population) and distance variables. The gravity approach can also be used to explain the determinants of bilateral foreign direct investment (FDI) between countries (Head and Ries, 2008). Accordingly, FDI patterns are expected to be proportional to the economic size of the involved investor and/or target countries. Interestingly however, some countries, offshore financial centers in particular, feature volumes of foreign investment which are 
disproportionate to their economic mass (Lane and Milesi-Ferretti, 2008, 2011; Hines, 2010). These volumes may reflect the intermediary role that offshore centers generally play in international finance (Lane and Milesi-Ferretti, 2011). At the same time, these patterns of FDI are also consistent with international tax avoidance involving the use of offshore tax havens: Under many forms of international tax planning, multinational companies (MNCs) channel funds through corporate entities resident in low-tax countries. Funds attributed to these entities lead to inbound flows of direct investment.

The first OECD indicator takes up this notion and attempts to measure BEPS by sorting countries into two groups according to whether they feature highly disproportionate volumes of inbound FDI - or not. The grouping of countries is based on FDI-to-GDP ratios, where a ratio above $200 \%$ is considered to reflect disproportionate volumes of FDI. After sorting countries into the two groups and computing the average FDI-to-GDP ratio for each group, a ratio of the averages is constructed in order to give the indicator. Figure 2 illustrates the idea with countries showing disproportionate FDI-to-GDP ratios marked in blue and all other countries marked in green.

\section{Figure 2: Illustration of indicator 1}

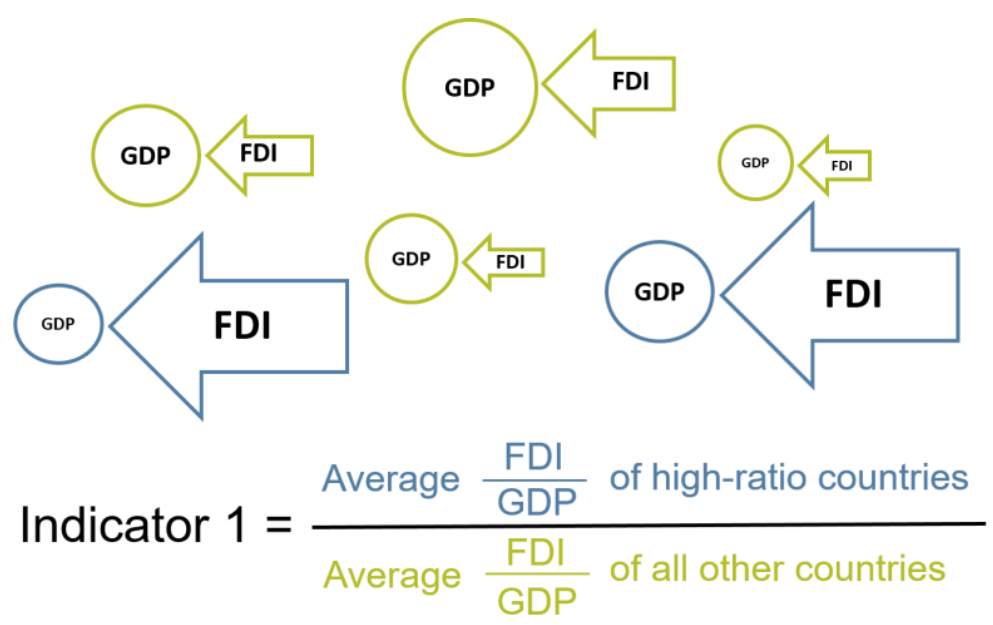

Admittedly, very high levels of inward FDI relative to GDP might signal BEPS-motivated FDI components routed through countries with little association to local value creation. Carefully considering the indicator, however, its weaknesses become apparent: The FDI-to-GDP ratio is influenced by numerous economic factors which relate, for example, to the structure of a country's economy as well as domestic savings. Moreover, the ratio may reflect growth or the business cycle with (foreign) investment being particularly strong in thriving economies. At the same time the denominator, i.e. GDP is subject to business cycle effects as well. After all, the proposed FDI-to-GDP threshold of (at least) $200 \%$ used to classify countries appears arbitrary 
and there is no exogenously given benchmark which separates data patterns reflecting BEPS components from those which do not include investment motivated by BEPS. These problems already hold for gross FDI. Net FDI and an indicator built thereon are even more difficult to interpret because tax attractive countries can plausibly feature both high and low levels of net FDI depending, for example, on whether a country serves as an important conduit of FDI or entities tend to invest in portfolio assets.

For illustrative purposes, we calculate (gross) FDI-to-GDP ratios in Table 1 for a small selection of countries and categorize them according to the $200 \%$ threshold. It turns out that indicator 1 will certainly be driven by a few countries such as Luxembourg and the Marshall Islands that feature extreme FDI-to-GDP ratio even within the group of tax havens. Moreover, the somewhat arbitrary threshold of a $200 \%$ ratio becomes apparent given that Singapore, an important offshore location, is in the non-haven group with its FDI-to-GDP ratio of about $171 \%$. FDI stocks invested in Ireland and the Netherlands are very high but the size of these economies puts the numbers into perspective. Whether FDI related to real activity in these countries or is tax motivated remains an open question.

Table 1: FDI-to-GDP ratios for a selection of countries

\begin{tabular}{l|r|r|} 
& \multicolumn{1}{|c|}{ GDP } & \multicolumn{1}{|c|}{ FDI-to-GDP } \\
\hline High ratio countries (FDI-to-GDP $>\mathbf{2 0 0} \%$ ) & 11,839 & \\
Bahamas & 304,819 & $373.20 \%$ \\
Ireland & 58,631 & $472.10 \%$ \\
Luxembourg & 194 & $2011.05 \%$ \\
Marshall Islands & 777,228 & $344.14 \%$ \\
Netherlands & & \\
$\ldots$ & & \\
Low ratio countries (FDI-to-GDP $<\mathbf{2 0 0 \% )}$ & $3,477,796$ & $21.60 \%$ \\
Germany & $2,650,850$ & $109.39 \%$ \\
United Kingdom & $18,624,475$ & $22.11 \%$ \\
United States & 309,764 & $171.37 \%$ \\
Singapore & 3,765 & $10.65 \%$ \\
Virgin Islands & & \\
\hline
\end{tabular}

Notes: FDI data is obtained from OECD, GDP data is obtained from the World Bank.

The OECD documents that indicator 1 has risen during recent years from a value of 13 in 2005 to 26.7 in 2012 (OECD, 2015: p. 51). One can only speculate whether this highly aggregate macroeconomic indicator does tell us anything about the development of BEPS activity during this time period or whether other macroeconomic developments are responsible for the observed data patterns. 


\section{Indicator 2: High profit rates of low-taxed affiliates of top global MNCs}

The second BEPS indicator proposed by the OECD is based on firm-level data and requires data on multinational group structures. Once the structure of a multinational group has been identified, the affiliates of the MNC are grouped along two dimensions. First, the affiliates are classified according to whether their effective tax rate lies below or above the MNC's consolidated global effective tax rate. Second, affiliates are grouped according to their profit rate (pretax income over assets) relative to the MNC's worldwide profit rate. Eventually, affiliates are divided into four quadrants along these dimensions: A first quadrant that includes affiliates featuring a (relatively) low profit rate and a (relatively) high tax burden, a second quadrant with both (relatively) low profit and tax rates, a third quadrant with both (relatively) high profit and tax rates, and a fourth quadrant that includes those affiliates which are highly profitable but feature low effective tax rates.

Figure 3: Illustration of indicator 2

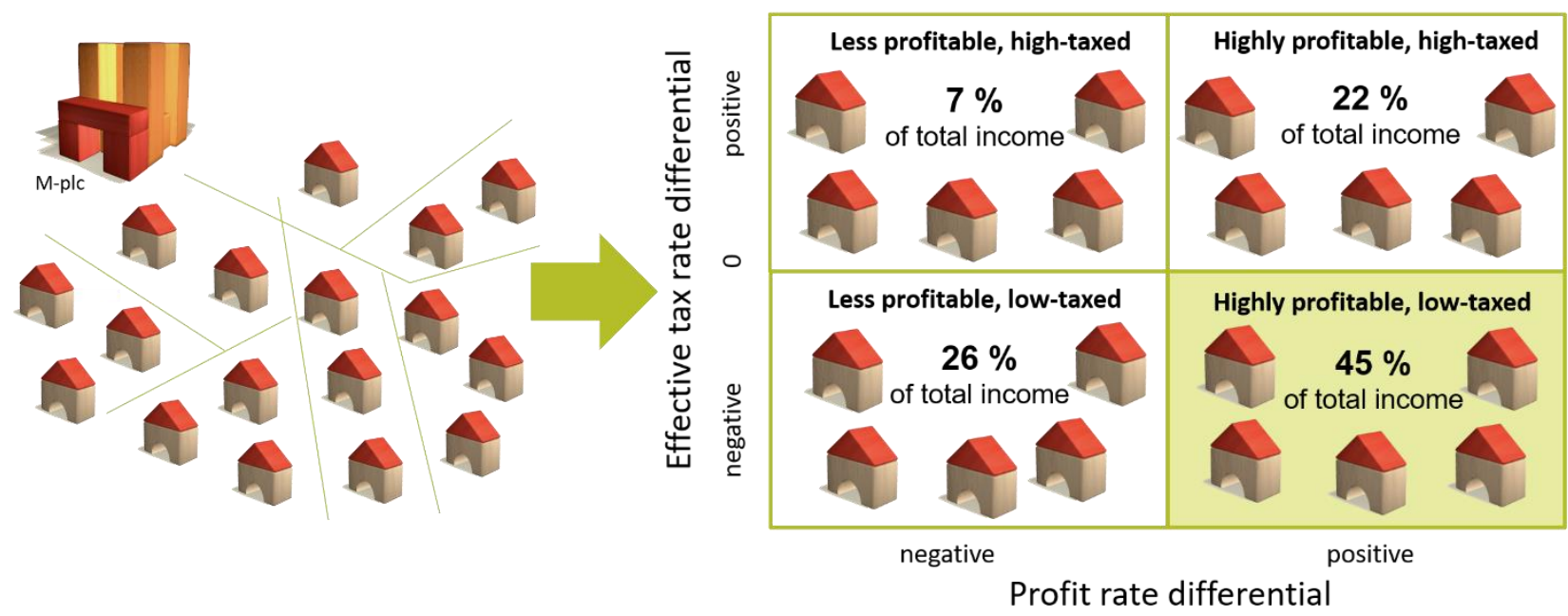

Source: This figure is, in parts, based on OECD (2015): p. 51, Figure 2.3

The indicator which is ultimately calculated on the basis of this affiliate sorting reflects the proportion of the MNC's total income reported by the affiliates in the fourth quadrant - with calculations repeated and averaged across an entire sample of MNCs. The underlying intuition is clear: From a pure tax perspective, income is optimally allocated to affiliates that are low taxed, driving up profit margins in these jurisdictions. The larger the scale of BEPS, the more income should be allocated accordingly. 
Based on data for the 250 top global MNCs in 2015, the OECD calculates that $45 \%$ of total income is, on average, reported in the high profits - low tax group of affiliates (see Figure 3).

BEPS activity might, among other factors, be driving this result. Still, the information content of this second indicator remains, similar to the first indicator, only vague. Specifically, the indicator provides no indication about whether income attributed to profitable low-tax affiliates originates from their real productive activity or from profit shifting. Companies have strong incentives to allocate profitable investment projects to low-tax countries as has been shown for the case of R\&D projects by Ernst et al. (2014). R\&D investment can boost profit rates calculated on the basis of total assets reported in balance sheets. On the basis of the proposed indicator, shifting profitable economic activity towards tax attractive countries thus cannot be reliably separated from profit shifting in its strict sense. Moreover, similar to the first indicator, there is no benchmark or counterfactual scenario that informs about how the data would look like if there was no profit shifting.

\section{Indicator 3: High profit rates of MNC affiliates in lower-tax locations}

The third BEPS indicator proposed by the OECD is also based on firm-level data and requires information on multinational group structures. The OECD proposes, for each individual MNC, to compute effective tax rates at the level of each country in which the multinational firm operates. Countries shall then be ranked by effective tax rates for each MNC. Starting with the lowest country ETRs, those countries which account for up to $20 \%$ of the group's worldwide assets are classified as low-tax countries.

Figure 4: Illustration of indicator 3

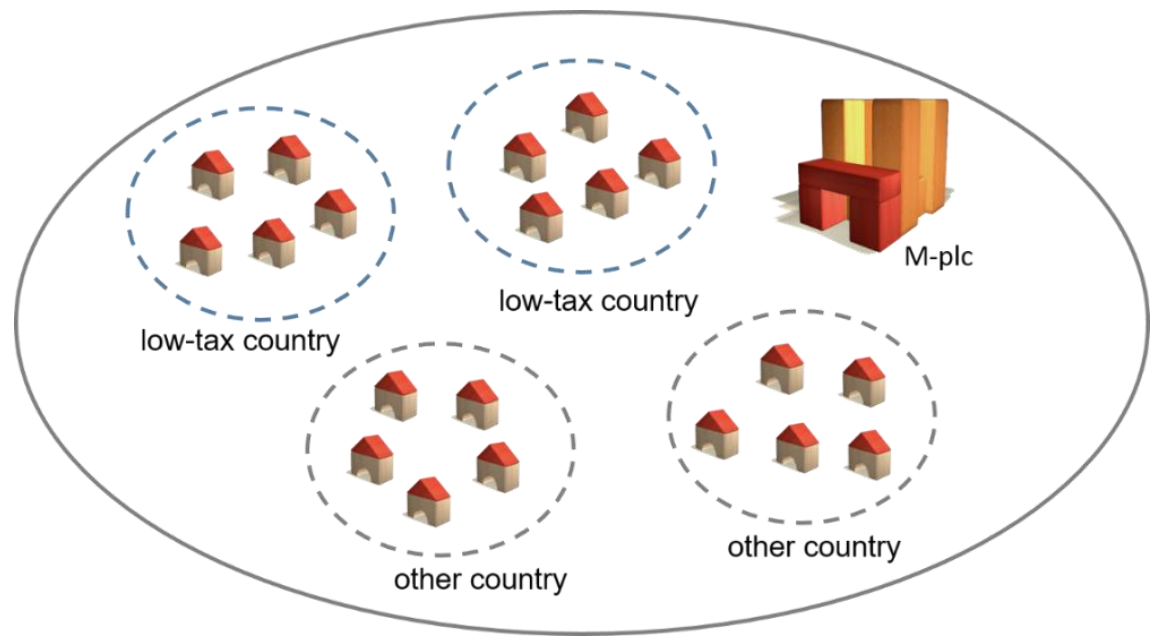




\section{Indicator $3=\begin{gathered}\text { Asset-weighted average } \\ \text { over } 250 \text { top MNCs }\end{gathered}\left(\frac{\text { Average profit rate in low-tax countries }}{\text { Worldwide profit rate of MNC }}\right)$}

For each MNC, its average profit rate in this group of low-tax countries is divided by the overall worldwide profit rate of the group (see the formula in Figure 4). The notion underlying this indicator thus is similar to the second one as are its fundamental weaknesses. In particular, the definition of low-tax countries seems arbitrary. The indicator is calculated as the asset-weighted average over the 250 top global MNCs and takes on values of 1.9 in 2007 and 2.0 in 2011 (OECD, 2015).

\section{Indicator 4: MNCs vs. "comparable" non-MNC effective tax rate differentials}

The first indicator discussed above relies on highly aggregate data while many factors potentially driving the data remain uncontrolled. The second and third indicators employ microdata at the level of the multinational group. Still, these two alternative approaches, as discussed, do not allow for a clear-cut separation of the international income allocation that stems from the geographical distribution of MNCs' value chains from the consequences of cross-border profitshifting towards low-tax countries. In other words, these approaches lack a meaningful counterfactual income allocation that mimics a situation without profit shifting opportunities.

The fourth indicator proposed by the OECD takes up this critical point and aims to assess the observed income allocation within MNCs with reference to a comparison group that reflects a counterfactual benchmark. For this purpose, a sample including both multinational group affiliates and domestic non MNC-entities is assembled from firm-level databases. Domestic firms do not have access to international profit shifting opportunities and, controlling for other relevant determinants, a comparison of suitable outcome variables between domestic and multinational companies might reveal the influence and scale of BEPS. Thus, exploiting this combined data sample, the OECD proposes to regress the companies' effective tax rates on a binary dummy variable that marks the multinational affiliates in the sample, conditional on a set of further ETR determinants that might correlate with MNC-status (size, industry etc.). If the coefficient of the binary dummy variable loads negative and significant, this is considered as an indication for profit shifting opportunities driving down effective tax rates of multinational affiliates relative to domestic companies. 


\section{Figure 5: Illustration of indicator 4}

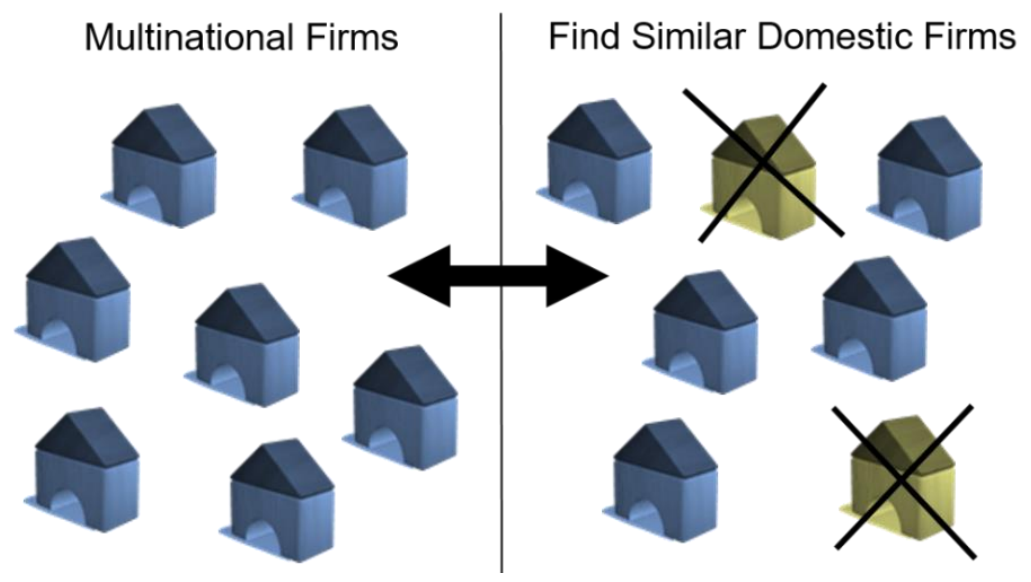

The strength of this approach lies in the fact that it acknowledges the need for a counterfactual benchmark in order to gauge the implications of profit shifting opportunities arising within multinational groups. However, the quality of the comparison depends on how similar and comparable the groups, i.e. multinational affiliates and domestic stand-alone firms, actually are. The approach, thus, has to be enhanced by statistical matching procedures. In particular, self-selection has to be addressed: Since very profitable firms are more likely to expand across borders than less profitable or even loss-making businesses, a naive comparison of tax outcomes between multinational firms and domestic firms is misleading. So-called propensity score matching provides, under several assumptions, a solution for this econometric problem. The propensity score matching approach features analogies to experimental settings (Rubin, 1974; Rosenbaum and Rubin, 1983; Lechner, 2002). The key idea is to determine a control group (in the given context: domestic firms) which is similar to the treatment group (here: the multinationals) with respect to as many criteria as possible, and which allows for a meaningful comparison of the outcome variable for these two groups. The relevant propensity score can be estimated as the predicted probability of belonging to the treatment group or the control group conditional on a set of observable characteristics. 
Moreover, any study should use a suitable outcome variable. Considering the OECD approach, it seems questionable whether the effective tax rate is the optimal variable to measure discrepancies between multinationals and domestic firms that have been caused by BEPS activity. The effective tax rate is defined as tax expense divided by reported pre-tax income of an affiliate. It reflects consequences of so called non-conforming tax avoidance leading to mismatches between income for financial accounting purposes and taxable income. While it may thus reflect, for example, certain forms of hybrid mismatches or preferential tax treatments, the ETR will neither signal profit shifting via tax efficient transfer pricing nor tax planning involving tax optimal allocation of interest or royalty expenses. Other types of variables might thus be more informative to assess the BEPS opportunities and activities of multinational firms.

Considering the empirical literature, Egger et al. (2010) and Finke (2015) analyze profit shifting activity relying on approaches that represent best practice. Egger et al. (2010) directly compare tax payments of multinational firms to those of domestic firms which they select using propensity score matching. They are able to document that foreign owned subsidiaries located in countries with above average tax rates pay on average 1.266 million Euro less taxes than domestically owned firms in the control group. This is about $30 \%$ of the tax payments of the control group. Enhancing the approach by Egger et al. (2010), Finke (2015) uses observable firm characteristics instead of only regional characteristics to match multinational and domestic firms. Consistently, she finds that German MNCs pay about $27 \%$ less tax than the control group of domestic firms. However, after the 2008 major German tax reform, which cut tax rates and implemented stricter anti-avoidance legislation, the difference in tax payments between multinationals and domestic firms shrinks to about half of the pre-reform effect.

In sum, relying on the definition of a comparison group, indicator 4 presents the most promising approach to identify BEPS activity in a conceptually sound way. Using state-of-the-art statistical methods and plausible outcome variables for comparison, BEPS activity can be consistently traced.

\section{Indicator 5: Profit shifting through intangibles}

The OECD's proposed fifth indicator gets back to aggregate macroeconomic data rather than firm-level data. The approach concentrates on one specific form of profit shifting involving the use of intangible assets and associated royalty payments toward low tax countries. The idea is to identify countries which, relative to the actual R\&D activity taking place, feature a disproportional volume of inbound royalty payments. In that sense, the indicator resembles the first 
indicator that also tried to identify BEPS using aggregate proportions - and again no clear benchmark for the assessed proportionality is provided. Above a ratio of 50\%, countries are classified as featuring a disproportionate volume of inbound royalty flows to aggregate business $R \& D$ expenditure. The average royalty-to- $R \& D$ ratio of this group of countries ${ }^{3}$ divided by the average ratio calculated for the remaining countries defines the indicator.

\section{Figure 6: Illustration of indicator 5}

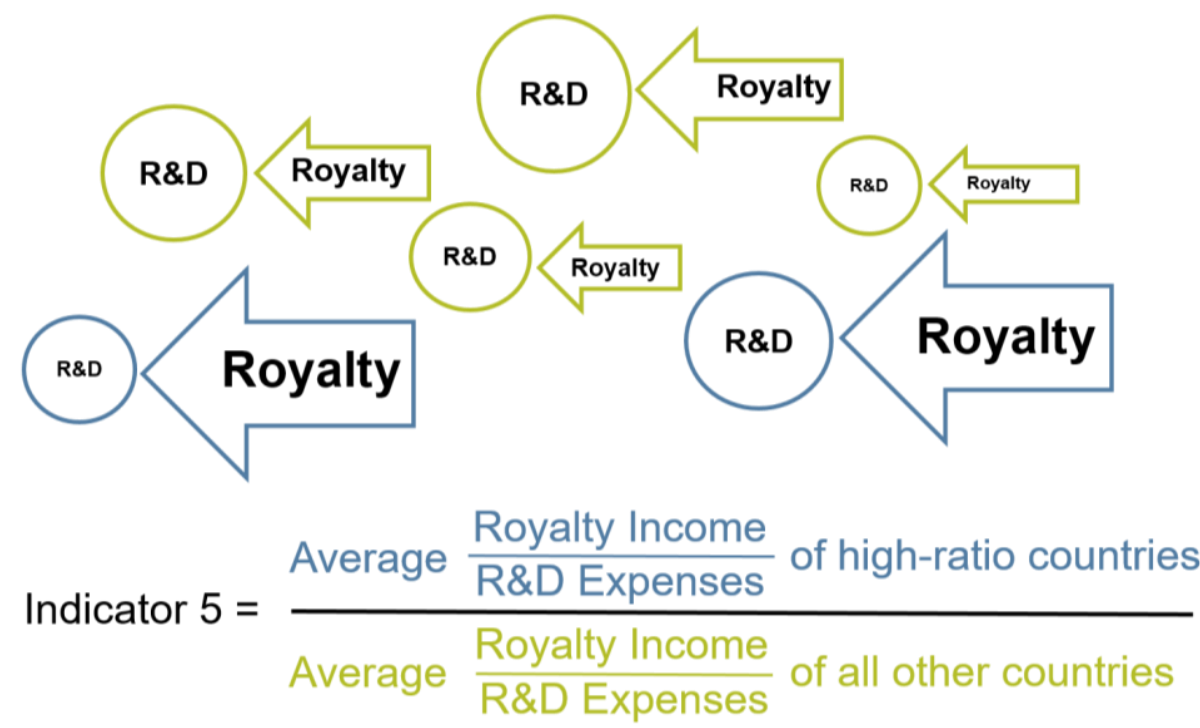

While the focus on one specific form of profit shifting, i.e. tax planning involving R\&D and the resulting intangible property, may be considered as an advantage of the indicator, it presents weaknesses similar to indicator 1. Importantly, MNCs can locate highly profitable R\&D activity in low-tax jurisdictions (Ernst et al., 2014). Such investment behavior clearly involves tax considerations; however, it reflects real consequences of the international tax differential rather than BEPS activity. Moreover, R\&D expenditures are highly cyclical. In addition, there is a considerable time lag between R\&D expenditures and royalty income. Thus, the considered ratio might vary depending on the business cycle and the dynamics of $R \& D$ expenditures. Considering royalty flows, an important share of this aggregate position might not be linked to R\&D output but to the use of trademarks, copyrights or franchises. Whether R\&D expenditure alone is the right denominator thus seems questionable as long as the considered royalty data is not consistently defined.

\section{Indicator 6: Profit shifting through interest}

\footnotetext{
${ }^{3}$ Country grouping is based on data as of 2011 and held constant.
} 
Indicator 6 returns to using micro data and is somewhat similar to indicator 2 as it groups the affiliates of MNCs along two dimensions. First, the affiliates are classified according to whether their statutory profit tax rate lies below or above the MNC's weighted (by EBITDA) average statutory tax rate. Second, affiliates are grouped according to whether their interest-to-income ratio, defined as interest paid divided by EBITDA, exceeds or falls below the MNC's consolidated worldwide interest-to-income ratio. Eventually, the affiliates are thus divided into four quadrants. This type of division is done for the 250 top global MNCs. For each quadrant, the difference between the weighted average interest-to-income ratio of affiliates in that specific quadrant and the weighted average interest-to-income ratio of all affiliates is calculated and called the "excess ratio". The excess ratio of the northeast quadrant, i.e. for the high-tax and high interest-to-income affiliates, is indicator six.

While this indicator tries to measure excessive interest deductions as one of the most important debt channels (OECD, 2015: p. 63), it ignores that increased debt levels in high-tax locations might reflect domestic tax incentives (Modigliani and Miller, 1963) just as well as international profit shifting incentives.

\section{Figure 7: Illustration of indicator 6}
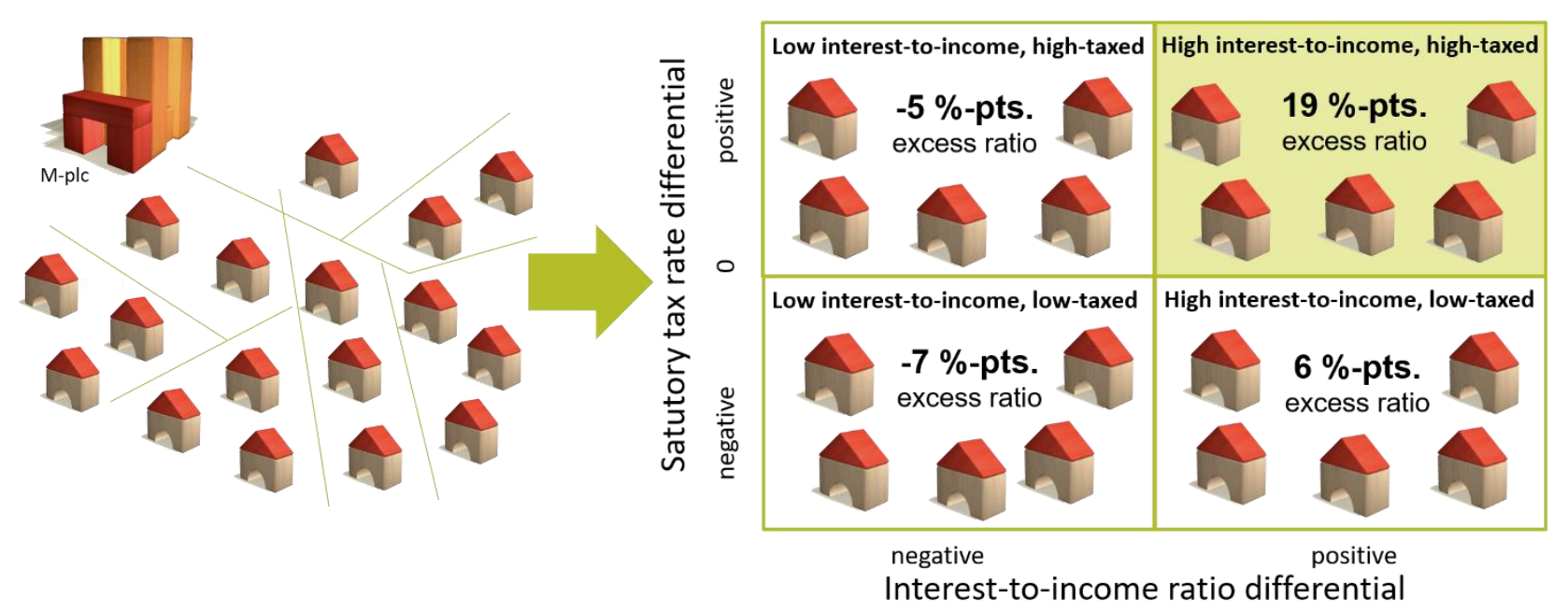

Source: This figure is, in parts, based on OECD (2015): p. 64, Figure 2.6

\section{Conclusions}

Given that our current knowledge of income shifting behavior is still far from complete, every new indicator seems worth considering. Especially a certain need for "easy-access" indicators 
to measure the relevance of the base erosion problem seems to be justified. In this paper, we discuss whether the proposed OECD indicators indeed represent methodological advances and critically assess their informative value. Overall, we are skeptical.

- Indicator 1 might be the weakest indicator for the scale of BEPS as there are too many other influences on FDI; yet it might point to abnormal high FDI locations to be investigated more closely.

- Similarly, indicators 2 and 3 are not able to precisely signal the separation of economic value creation and taxable income.

- Indicator 4 could be a good proxy for scale of BEPS, depending on the quality of the applied matching process.

- Indicators $5 \& 6$ focus on single BEPS channels; therefore, they might be somewhat more focused and less affected by confounding factors but indicator 5 uses macro-level data and potential time-lags between $R \& D$ expenses and resulting royalty payments could create noise.

In sum, our discussion shows that the indicators present shortcomings, many of them acknowledged by the OECD (2015) itself, that prevent them from very reliably tracing profit shifting activity in available international data. With one notable exception, the OECD's indicators lack consistent counterfactuals and comparison groups which are essential benchmarks for the observed data. Only one of the proposed approaches to measure BEPS, i.e. indicator 3, explicitly acknowledges the need for such a counterfactual benchmark and thus could form the basis of a reliable measure for BEPS, supposing that sound and state-of-the-art statistical techniques are applied. We highlight that this type of studies does exist.

Still, even the most promising approaches require representative and timely data that covers firms' global activity, including tax haven operations. With better access to such high-quality micro-level data, it will be easier to empirically isolate the effects of profit shifting from relocations of real economic activity and value creation.

\section{References}

Barrios, Salvador, and Diego d'Andria (2016). Estimating Corporate Profit Shifting with FirmLevel Panel Data: Time Trends and Industrial Heterogeneity. JRC Working Papers on 
Taxation and Structural Reform No 7/2016, European Commission, Joint Research Centre, Seville.

Clausing, Kimberly A. (2016). The Effect OF Profit Shifting on the Corporate Tax Base in the United States and Beyond. National Tax Journal 69: 905-934.

Dharmapala, Dhammika (2014). What Do We Know about Base Erosion and Profit Shifting? A Review of the Empirical Literature. Fiscal Studies 35: 421-448.

Egger, Peter, Wolfgang Eggert, and Hannes Winner (2010). Saving Taxes Through Foreign Plant Ownership. Journal of International Economics 81: 99-108.

Ernst, Christof, Katharina Richter, and Nadine Riedel (2014). Corporate Taxation and the Quality of Research and Development. International Tax and Public Finance 21 (4): 694719.

Finke, Katharina (2015). What is the scale of profit shifting: Evidence from a propensity score matching approach and propensity score reweighting. Working Paper.

Head, Keith, and John Ries (2008). FDI as an Outcome of the Market for Corporate Control: Theory and Evidence. Journal of International Economics 74: 2-20.

Heckemeyer, Jost H., and Michael Overesch (2017). Multinationals' Profit Response to Tax Differentials: Effect Size and Shifting Channels. Canadian Journal of Economics 50 (4): 965-994.

Hines, James R., and Eric M. Rice (1994). Fiscal Paradise: Foreign Tax Havens and American Business. Quarterly Journal of Economics 109(1): 149-182.

Hines, James R. (2010). Treasure Islands. Journal of Economic Perspectives 24 (4): 103-126.

Huizinga, Harry, and Luc Laeven (2008). International Profit Shifting within Multinationals: A Multi-Country Perspective. Journal of Public Economics 92(5-6): 1164-1182.

Klassen, Kenneth J., and Stacie K. LaPlante (2012). Are U.S. Multinational Corporations Becoming More Aggressive Income Shifters?. Journal of Accounting Research 50(5): $1245-1285$.

Lane, Philip R., and Gian Maria Milesi-Ferretti (2008). International Investment Patterns. The Review of Economics and Statistics 90: 538-549. 
Lane, Philip R., and Gian Maria Milesi-Ferretti (2011). Cross-Border Investment in Small International Financial Centres. International Finance 14: 301-330.

OECD (2015). Measuring and Monitoring BEPS, Action 11 - 2015 Final Report, OECD/G20 Base Erosion and Profit Shifting Project. Paris: OECD Publishing. DOI: http://dx.doi.org/10.1787/9789264241343-en

Riedel, Nadine (2014). Quantifying International Tax Avoidance: A Review of the Academic Literature. Paper prepared for the European Tax Policy Forum.

Rosenbaum, Paul R., and Donald B. Rubin (1985). Constructing a Control Group Using Multivariate Matched Sampling Methods that Incorporate the Propensity Score. American Statistician 3: 33-38.

Rubin, Donald B. (1974). Estimating Causal Effects of Treatments in Randomized and Nonrandomized Studies. Journal of Educational Psychology 66: 688-701.

Sullivan, Martin A. (2012). Apple Reports High Rate but Saves Billions on Taxes. Tax Notes 134: 777-778. 
Download ZEW Discussion Papers from our ftp server:

http://ftp.zew.de/pub/zew-docs/dp/

or see:

https://www.ssrn.com/link/ZEW-Ctr-Euro-Econ-Research.html

https://ideas.repec.org/s/zbw/zewdip.html

$$
\text { // }
$$

IMPRINT

ZEW - Leibniz-Zentrum für Europäische Wirtschaftsforschung GmbH Mannheim

ZEW - Leibniz Centre for European

Economic Research

L 7,1 68161 Mannheim · Germany

Phone +49621 1235-01

info@zew.de·zew.de

Discussion Papers are intended to make results of ZEW research promptly available to other economists in order to encourage discussion and suggestions for revisions. The authors are solely responsible for the contents which do not necessarily represent the opinion of the ZEW. 